\title{
Research Trends in STEM Education from 2011 to 2020: A Systematic Review of Publications in Selected Journals
}

\author{
https://doi.org/10.3991/ijim.v16i05.27003
}

Irwanto Irwanto ${ }^{1(凶)}$, Anip Dwi Saputro ${ }^{2}$, Widiyanti ${ }^{3}$, M. Firman Ramadhan ${ }^{4}$, Isna Rezkia Lukman ${ }^{5}$

${ }^{1}$ Department of Chemistry Education, Universitas Negeri Jakarta, Jakarta, Indonesia

${ }^{2}$ Faculty of Islamic Studies, Universitas Muhammadiyah Ponorogo, Ponorogo, Indonesia

${ }^{3}$ Department of Mechanical Engineering, Universitas Negeri Malang, Malang, Indonesia ${ }^{4}$ Department of Physics Education, Universitas Muhammadiyah Mataram, Mataram, Indonesia ${ }^{5}$ Department of Chemistry Education, Universitas Malikussaleh, Aceh, Indonesia

irwanto@unj.ac.id

\begin{abstract}
Nowadays, STEM education plays an essential role in the economic growth and competitiveness of nations. This systematic review was aimed to reveal research trends in STEM education over the last 10 years. A total of 336 studies published in the Journal of Science Education and Technology, Research in Science Education, Journal of Science Teacher Education, International Journal of Science Education, Journal of Research in Science Teaching, and Science Education were selected for analysis. The time span was limited to the period between 2011 to late 2020. All sample papers were then examined to capture the latest research trends and status regarding STEM education that included the number of papers by year, research types, countries' rank, and the number of authors. To collect data, the formula proposed by Howard et al. [1] was employed to determine the most productive countries in terms of STEM education scholarships. Findings revealed that STEM education has garnered greater attention and it grew rapidly within this period. The most frequent research type used in STEM education were quantitative studies. In addition, the US, Australia, and the Netherlands were the most productive countries in STEM education research. During these ten years, most papers published in selected journals were written by three authors. This indicates that STEM education is an attractive topic to explore collaboratively by researchers and educators around the world.
\end{abstract}

Keywords-literature review, research trends, STEM education, systematic analysis

\section{Introduction}

In the 1990s, the National Science Foundation (NSF) integrated the disciplines of Science, Technology, Engineering, and Mathematics to form the acronym STEM [2], an interdisciplinary approach originally unified using the term SMET (Science, Mathematics, Engineering, and Technology) and introduced in the United States. Now, the term STEM is getting more popular at various levels of education in the last decade. However, the definition of STEM education varies in the literature. 
According to Moore et al. [3], STEM education refers to how teachers combine some or all of the four disciplines of science, technology, engineering, and mathematics based on the relationship between subjects and real-world issues. Then, Johnson [4] revealed that STEM is "an instructional approach, which integrates the teaching of science and mathematics disciplines through the infusion of the practices of scientific inquiry, technological and engineering design, mathematical analysis, and $21^{\text {st }}$ century interdisciplinary themes and skills" (p. 367). Recently, Martin-Paez et al. [5] argued that "STEM teaching must be based on the standards of STEM curricula, creating experiences for students that allow them to develop STEM proficiency. These experiences should include participation in research, logical reasoning, and problem-solving" (p. 803). Despite some conceptualizations that exist, STEM education is generally seen as a classroom teaching approach that combines STEM disciplines. This interdisciplinary approach is used to develop students as competent problem solvers and to improve learning activities [6-7]. In short, STEM education aims to find solutions to real-world problems as well as to provide students with more relevant experiences and prepare them for future career paths.

Unfortunately, in the previous literature [8-11], the majority of students had a lower interest in learning STEM-related subjects and their motivation to pursue a career in this field was relatively low. In turn, this may lead to a decline in the number of STEM professionals worldwide. For example, in 2007, the European Union released that young people's knowledge of science declined significantly [12]. In addition, in the US, Sadler et al. [13] found weak interest in STEM-related careers among students. Similarly, Kennedy et al. [14] revealed that STEM enrolments in Australian high schools also declined. In the Asian context, Wahono et al. [10] stated that students seemed to have a weak interest in subjects related to STEM. In particular, Kim et al. [8] added that Korean students showed their disinterest in science and mathematics in the last two decades. In general, students' interest in science and technology decreases with their school years [9]. This situation indicates that more students avoid STEM subjects. In fact, STEM education has been claimed as an appropriate platform to develop highly qualified workers and promote economic development [15-16].

Responding to these problems, STEM education is becoming an international focus in preparing students for the demands of future transdisciplinary careers [17]. Over the past decade, numerous studies in STEM education have been conducted at various levels of education in many countries [9, 17-19]. Many benefits associated with STEM education have been reported. For example, integrating STEM disciplines into the classroom provides opportunities for students to be more engaged in their own learning, develops problem-solving skills and creativity, and promotes their higher-order thinking skills through exposure to real-world problems [6, 20]. Previous studies also reported that STEM-related activities increased students' critical thinking and collaboration and their interest and knowledge in pursuing STEM-related careers [21-22]. Thus, STEM subjects are effective means to produce competitive graduates for better global competitiveness in the $21^{\text {st }}$ century [18]. This expectation is reasonable since the STEM setting encourages students to engage in mathematical analysis, scientific inquiry, and technological and engineering design $[6,23]$ in order to develop $21^{\text {st }}$ century skills that are regarded as essential skills for success in future careers [24].

Developed countries such as the US, Australia, Canada, and the UK have emphasized the importance of having more graduates with high-level STEM skills to foster 
innovation, promote productivity growth, and compete for the global competition $[16,24-25]$. For example, in the UK, the public is involved in STEM education in the forms of STEM activities for communities, in museums, and informal science centers to encourage students' engagement in STEM [25]. Then, Australia and India reportedly collaborated to redesign the national STEM strategy to produce a skilled workforce capable of bringing a positive contribution to the STEM industries of the two countries [16]. Since 2002, Norway has also developed a strategic plan for STEM to improve teachers' skills in teaching STEM at all levels of education [19]. In 2011, South Korea issued a national policy that integrates science, technology, engineering, arts, and mathematics education to prepare the workforce with strong STEM skills [26]. It is a fact that many countries have started to integrate STEM activities into their school curricula to meet the need for a skilled workforce in STEM fields.

Internationally, the current state of STEM education research has been welldocumented in the previous literature. For example, Bozkurt et al. [27] identified research trends in 258 articles published between 2014 and 2016 in a systematic review study. Then, Ozkaya [28] conducted a bibliometric analysis of 2313 papers published between 1992 and 2017 retrieved from the Web of Science database. In addition, Li et al. [29] conducted a systematic analysis on 798 studies published between 2000 and 2018. Gil-Domenech et al. [30] also presented a bibliometric overview of 474 papers in STEM education between 1991 and 2016 from the Web of Science database. Most recently, Takeuchi et al. [31] evaluated 2171 publications published between January 2007 to December 2017 from the EBSCO database. However, it should be noted that previous studies [27-31] generally only provided research trends in STEM education until 2018. Aiming to present a more holistic perspective, this study analyzed the trends and patterns of publications related to STEM education from 2011-2020 through a systematic review. Conducting a systematic review of publications in academic journals may assist STEM educators and researchers to investigate the current status and future trends in the field of STEM education. Also, this review provides a more comprehensive analysis of the previous literature in this area. By compiling a large volume of STEM education literature, the findings of the current study may be useful in guiding future studies [32]. The questions of this study were proposed as follows:

1. How is the academic trend in STEM education literature published between January 2011 to December 2020?

2. How is the distribution of papers by research type?

3. Which countries are the most productive in terms of STEM education research?

4. How is the pattern of authorship in STEM education publications?

\section{Method}

\subsection{Design}

This systematic review was conducted using a protocol designed by Tsai and Wen [33] and Li et al. [29]. Articles that were analyzed in this systematic review had met predetermined criteria. For instance, they should be written in English, published between January 2011 and December 2020, and only published in six major academic 
journals. Data were collected on May 11, 2021, and the researchers did not include any articles between January to May 2021. To analyze the data, descriptive statistics including frequencies and percentages were also calculated.

\subsection{Identifying selected journals}

The current study involved several papers published in international journals indexed in the Social Science Citation Index (SSCI) of Web of Science. They were:

a. Journal of Science Education and Technology (JSET, founded in 1992)

b. Research in Science Education (RISE, founded in 1971)

c. Journal of Science Teacher Education (JSTE, founded in 1989)

d. International Journal of Science Education (IJSE, founded in 1979)

e. Journal of Research in Science Teaching (JRST, founded in 1963)

f. Science Education (SE, founded in 1916)

The selected journals were ones related to STEM teaching and learning with high impact factors. In the initial search, there were 1779 results within the 2011-2020 timespan.

\subsection{Identifying sample articles}

To collect relevant papers for review, the researchers employed the term "STEM", or "STEM education", or "science, technology, engineering, and mathematics", or "STEAM" as a searching keyword. It should be noted that book chapters, responses, book reviews, editorial sections, corrections, commentaries, and conference papers were excluded from the study. After a literature search, the final number in this study was 336 papers and they were then analyzed to gain the red line regarding research trends throughout a period of 10 years, including the number of papers per year, authors' nationality, types of research, and the number of authors in each paper. The analysis process was focused on the document titles, abstracts, keywords, and year of publication.

\subsection{Data analysis}

Authors' nationality. The researchers carried out manual coding to analyze the contribution of the authors' nationality. Each target paper was given 1 credit point. To determine the top 15 countries, the researchers employed a formula suggested by Howard, Cole, and Maxwell [1], in which the total number of authors $(n)$ and the order of the specific authors $(i)$ were put into consideration.

$$
\text { Score }=\frac{\left(1.5^{n-i}\right)}{\sum_{i-1}^{n} 1.5^{n-1}}
$$

If a paper was written by multiple authors from different countries, the points were divided based on certain proportions for each country [33]. The researchers then 
calculated the scores of each country in all sample papers. For example, if a paper was written by two authors from two different countries, where the first author was from Australia and the second author was from the Netherlands, then Australia was given 0.600 points and the Netherlands was given a score of 0.400 . In general, Table 1 visualizes the distribution of scores in a paper written by up to 10 authors.

Table 1. Scoring for countries based on the order of each author

\begin{tabular}{|c|c|c|c|c|c|c|c|c|c|c|}
\hline & \multicolumn{9}{|c|}{ Order of Every Author } \\
\hline $\begin{array}{c}\boldsymbol{N} \text { of } \\
\text { Authors }\end{array}$ & $\mathbf{1}$ & $\mathbf{2}$ & $\mathbf{3}$ & $\mathbf{4}$ & $\mathbf{5}$ & $\mathbf{6}$ & $\mathbf{7}$ & $\mathbf{8}$ & $\mathbf{9}$ & $\mathbf{1 0}$ \\
\hline 1 & 1.000 & & & & & & & & & \\
\hline 2 & 0.600 & 0.400 & & & & & & & & \\
\hline 3 & 0.474 & 0.316 & 0.211 & & & & & & & \\
\hline 4 & 0.415 & 0.277 & 0.185 & 0.123 & & & & & & \\
\hline 5 & 0.384 & 0.256 & 0.171 & 0.114 & 0.076 & & & & & \\
\hline 6 & 0.365 & 0.244 & 0.162 & 0.108 & 0.072 & 0.048 & & & & \\
\hline 7 & 0.354 & 0.236 & 0.157 & 0.105 & 0.070 & 0.047 & 0.031 & & & \\
\hline 8 & 0.347 & 0.231 & 0.154 & 0.103 & 0.069 & 0.046 & 0.030 & 0.020 & & \\
\hline 9 & 0.342 & 0.228 & 0.152 & 0.101 & 0.068 & 0.045 & 0.030 & 0.020 & 0.013 & \\
\hline 10 & 0.339 & 0.226 & 0.151 & 0.101 & 0.067 & 0.045 & 0.030 & 0.020 & 0.013 & 0.009 \\
\hline
\end{tabular}

Note: Adapted from Tsai and Wen [33].

Research type. Final sample papers were categorized into four types:

a. Qualitative (e.g., case study, narrative, document analysis, etc.)

b. Quantitative (e.g., quasi-experimental, survey, correlational, etc.)

c. Mixed methods

d. Non-empirical methods

Specifically, non-empirical methods consisted of theoretical or conceptual studies and literature reviews [29]. Each paper was assigned to only one research type.

\section{$3 \quad$ Results}

In this section, trends and patterns in STEM education scholarships published between early 2011 and late 2020 in 6 academic journals with long-term influence are explained. This systematic review provides an overview and research directions for researchers and educators in the field of STEM education. The findings are described in detail as follows. 


\subsection{Research trends of selected journals in STEM education between 2011-2020}

Figure 1 depicts the distribution of STEM education publications over the 10-year period. Specifically, among 336 studies, a total of 74 papers were published between the 2011-2015 period and 262 papers between the 2016-2020 period. The publication rate of the 5 years from 2016 to 2020 reached $77.98 \%$ of the total publications. The results indicated a significant increase from the first to the second five-year period. It can be simply inferred that STEM education remains an interesting topic for researchers and educators around the world to investigate.

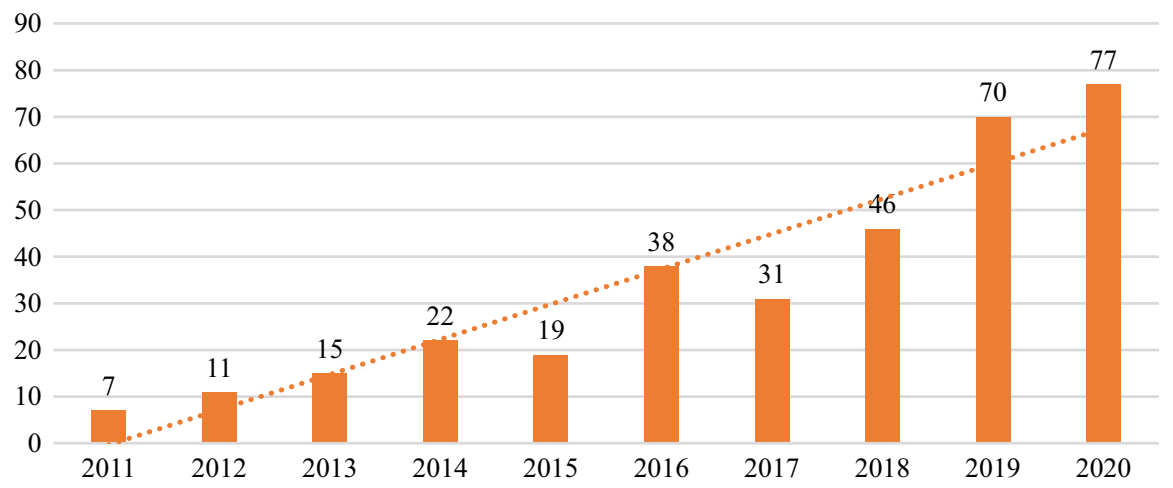

Fig. 1. Research trends of STEM education by year

The number of papers with and without the word STEM in the title is presented in Figure 2. There were 194 papers $(57.74 \%)$ using the acronym "STEM", or "STEM Education", or "STEAM", or the term "science, technology, engineering, and mathematics" in the titles and 142 papers in the abstracts or keywords. In the period between January 2011 and December 2020, the term STEM was more often used in the title than only in the abstract and/or keywords over years. In brief, more than half of the sample papers used the term STEM in their publication titles. This fact might be leading to more studies in STEM education in the future.

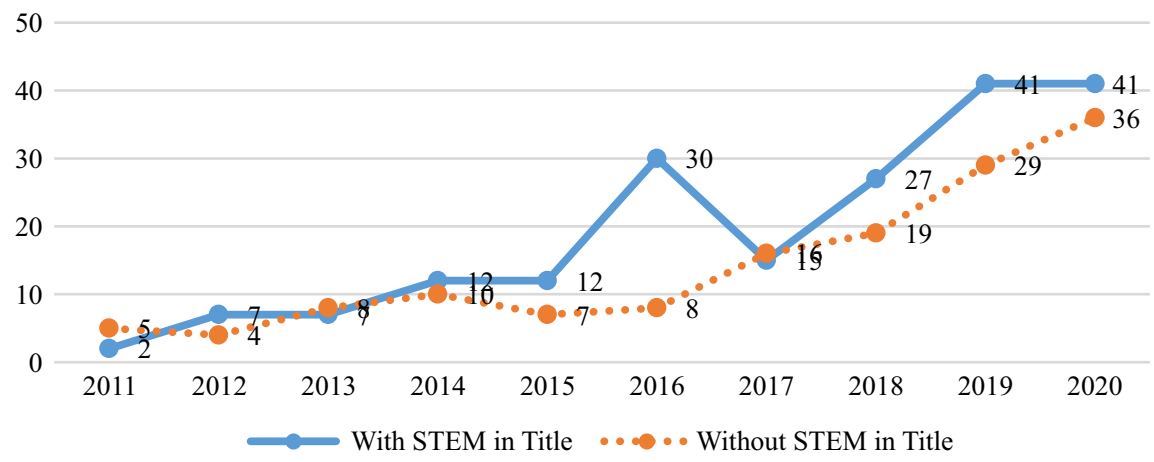

Fig. 2. The growth of publication trends with or without STEM in the titles 


\subsection{The number of published articles by research types}

Figure 3 shows the trend of research types from 2011 to 2020 . In this study, the researchers found that the most published papers in order are quantitative $(n=152$; $45.24 \%)$, qualitative $(n=94 ; 27.98 \%)$, mixed $(n=71 ; 21.1 \%)$, and non-empirical methods $(n=19 ; 5.65 \%)$. To date, quantitative studies have experienced a relatively sharp increase in terms of the number of publications from year to year, with the peak of publication in 2020 .

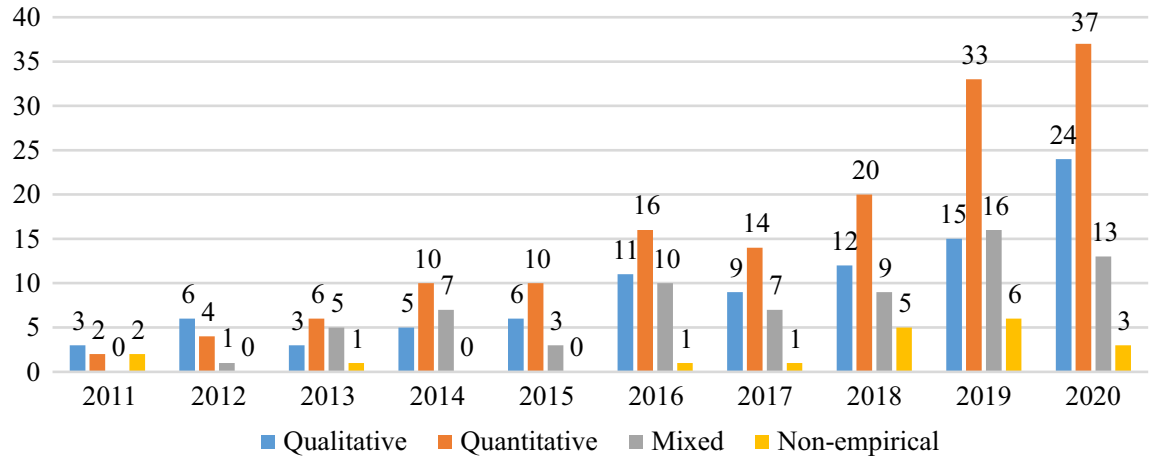

Fig. 3. Distribution of research types by year

When analyzed by journal, quantitative studies were rather published in almost all journals, except in JSTE. This indicates that quantitative research designs are popular over the past 10 years among STEM scholars. In addition, qualitative and mixedmethod research designs were mostly found in JSET. On the contrary, non-empirical studies have been published in at least all journals in 10 years. The analysis of the types of research is presented in Table 2.

Table 2. Number of papers by research types in selected journals from 2011 to 2020

\begin{tabular}{|l|c|c|c|c|c|c|}
\hline \multicolumn{1}{|c|}{ Type } & $\begin{array}{c}\text { JSET } \\
(\boldsymbol{n}=\mathbf{1 1 0})\end{array}$ & $\begin{array}{c}\text { RISE } \\
(\boldsymbol{n}=\mathbf{4 3})\end{array}$ & $\begin{array}{c}\text { JSTE } \\
(\boldsymbol{n}=\mathbf{1 3})\end{array}$ & $\begin{array}{c}\text { IJSE } \\
(\boldsymbol{n}=\mathbf{7 4})\end{array}$ & $\begin{array}{c}\text { JRST } \\
(\boldsymbol{n}=\mathbf{5 0})\end{array}$ & $\begin{array}{c}\text { SE } \\
(\boldsymbol{n}=\mathbf{4 6})\end{array}$ \\
\hline Qualitative & 24 & 10 & 7 & 20 & 15 & 18 \\
\hline Quantitative & 41 & 20 & 3 & 37 & 29 & 22 \\
\hline Mixed & 32 & 12 & 2 & 15 & 5 & 5 \\
\hline Non-empirical & 13 & 1 & 1 & 2 & 1 & 1 \\
\hline
\end{tabular}

\subsection{Most productive countries in STEM education research}

During the last 10 years, a total of 36 countries have contributed to STEM education literature. The score obtained by each country was calculated using the formula proposed by Howard et al. [1] and then sorted by the highest publication score. As a result, the researchers found that the US, Australia, and the Netherlands were the top three countries in STEM publications for both the 2011-2020 and 2016-2020 
periods (Table 3). Overall, these three countries have dominated $76.78 \%$ of all published articles in selected journals. Based on sites of study, most studies were conducted in Northern America (for example, US $=69.25 \%$ and Canada $=1.97 \%$ ). Only African countries did not represent in the top 15 countries. Instead, other countries outside the top 15 countries only contributed around $5.06 \%$ of publications.

Table 3. Top 15 countries with highest publication scores in STEM education

\begin{tabular}{|c|c|c|c|c|c|c|c|}
\hline \multirow{2}{*}{ Rank } & \multicolumn{3}{|c|}{$\mathbf{2 0 1 1}-\mathbf{2 0 2 0}$} & \multirow{2}{*}{ Rank } & \multicolumn{3}{|c|}{ 2016-2020 } \\
\cline { 2 - 3 } \cline { 7 - 8 } & Countries & Score & \% & & Countries & Score & \% \\
\hline 1 & US & 232.697 & 69.25 & 1 & US & 172.716 & 65.92 \\
\hline 2 & Australia & 15.085 & 4.49 & 2 & Australia & 15.085 & 5.76 \\
\hline 3 & Netherlands & 10.212 & 3.04 & 3 & Netherlands & 9.212 & 3.52 \\
\hline 4 & Israel & 9.106 & 2.71 & 4 & UK & 8.811 & 3.36 \\
\hline 5 & UK & 8.811 & 2.62 & 5 & Spain & 8.736 & 3.33 \\
\hline 6 & Spain & 8.736 & 2.60 & 6 & Canada & 6.207 & 2.37 \\
\hline 7 & Canada & 6.607 & 1.97 & 7 & Israel & 6.106 & 2.33 \\
\hline 8 & Germany & 5.959 & 1.77 & 8 & China & 5.889 & 2.25 \\
\hline 9 & China & 5.889 & 1.75 & 9 & Germany & 4.959 & 1.89 \\
\hline 10 & Denmark & 5.000 & 1.49 & 10 & Taiwan & 2.815 & 1.07 \\
\hline 11 & Taiwan & 2.863 & 0.85 & 11 & Turkey & 2.000 & 0.76 \\
\hline 12 & Slovenia & 2.047 & 0.61 & 11 & Denmark & 2.000 & 0.76 \\
\hline 13 & Turkey & 2.000 & 0.60 & 11 & Croatia & 2.000 & 0.76 \\
\hline 13 & Norway & 2.000 & 0.60 & 11 & Belgium & 2.000 & 0.76 \\
\hline 13 & Croatia & 2.000 & 0.60 & 15 & Ireland & 1.611 & 0.61 \\
\hline
\end{tabular}

\subsection{The distribution of the number of authors in STEM education publications}

To answer the last research question, the distribution of the number of authors for the period 2011-2020 is visualized in Figure 4. Overall, most papers have 3 authors $(n=80 ; 23.81 \%)$. A total of 79 papers $(23.51 \%)$ were five or more than five authored. Meanwhile, single-author papers were only 41 (17.56\%). When examined by journal, most of the papers published in JSET $(n=31)$ have at least 5 authors. Publications in RISE $(n=13)$, JSTE $(n=5)$, and IJSE $(n=22)$ were more frequently written by 3 authors each, and in JRST $(n=16)$ and SE $(n=11)$ were written by 2 authors. 


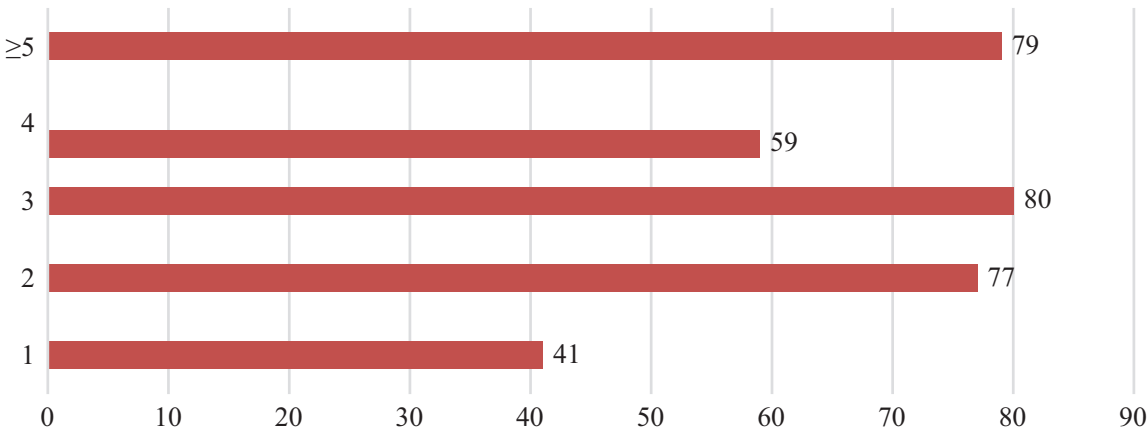

Fig. 4. The proportion of the number of papers with single or multiple authors

As shown in Figure 5, there is a significant increase in the number of three author papers between 2017 and 2020 . The total increase was $81.82 \%$. A similar trend was also found in the ones with four authors from 2011 to 2020. The number of papers in each category generally increased gradually during this period. This indicates an increase in collaborative research programs, either in a country or across countries among STEM affiliations.

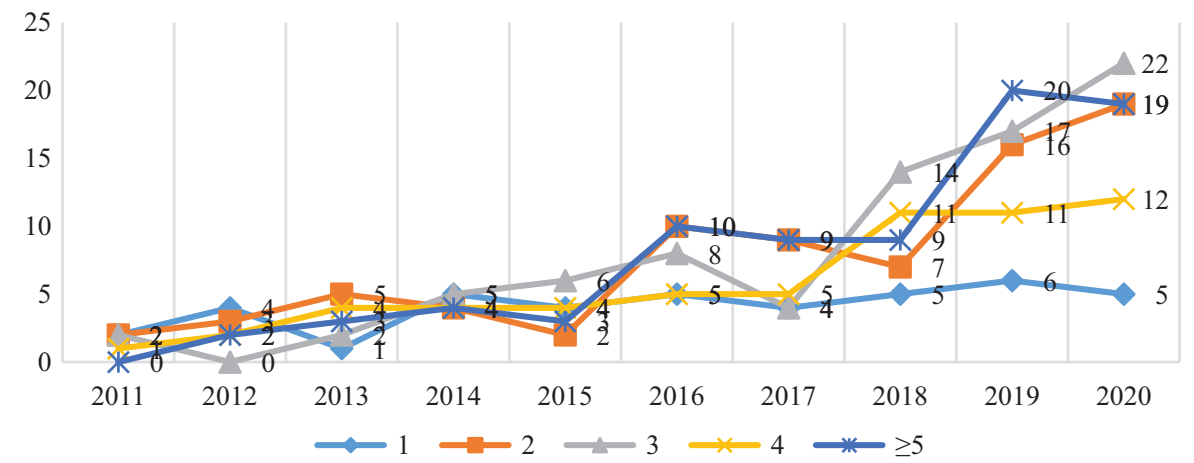

Fig. 5. Distribution of the number of authors by year

\section{Discussion}

The current study has successfully analyzed papers published in JSET, RISE, JSTE, IJSE, JRST, and SE from 2011 to 2020. Journals selected to examine were those with international scope in the field of STEM education in recent decades. Of the 336 papers, almost a third of the publications were published in JSET. This might occur since JSET has a wider scope (i.e., covers the intersection of science education and technology) than others and it publishes 6 times a year.

In this study, recent developments in STEM education publications are explained. The results of content analysis show a significant increase in the number of publications 
within these ten years. Since this topic is quite interesting, the researchers predict that there will be more papers regarding STEM education in the future. This result is similar to other STEM education trend studies [27-29, 31, 34-36]. For instance, Ha et al. [34] analyzed 175 publications retrieved from the Scopus database published between 2000 2019 among ASEAN countries. They found a rapid increase in the number of peer-reviewed articles in STEM education over the past 4 years (2016 to 2019). In a systematic review, Li et al. [29] examined 798 publications in STEM education from 2000 to the end of 2018 in 36 journals. They also reported that the number of research on STEM education has increased drastically from 2010 to 2018. In addition, Gil-Domenech et al. [30] identified 747 papers obtained from the Web of Science database published between 1991 to 2016. They reported that the majority of papers on STEM education were published after 2010, and the number of publications has substantially increased in recent years. The increasing number of publications in this field may be due to the increasing interest of researchers worldwide in STEM education [30, 35].

When papers are examined in terms of research types, it can be seen that the most published papers in the 2011-2020 period were quantitative studies (i.e., 45.24\%), followed by qualitative, mixed, and non-empirical studies. Similar findings were also found in previous reviews [27, 29, 31]. For instance, Bozkurt et al. [27] explored 258 papers indexed in the Scopus database to identify the current trends and patterns in STEM education between 2014 and 2016. They found that more than a third (i.e., $37.70 \%$ ) of the publications most commonly employed quantitative methods. Supportively, Li et al. [29] also identified 798 papers from 36 different journals in the 2000-2018 period and reported the number of papers adopting quantitative methods growth rapidly in recent years. Recently, Takeuchi et al. [31] reviewed 154 articles published between January 2007 to March 2018. The most frequently-used methods were surveys, a quantitative approach that allows data collection within a short time. Most studies were done using the quantitative methods probably because they could reach a broader audience, time and resources efficiently, easier data collection, and they allowed generalization [37-38].

Furthermore, analysis of the papers showed that among 36 countries, the US was the most productive country in STEM education scholarships from 2011 to 2020, followed by Australia, the Netherlands, and Israel. Not surprisingly, the dominance of developed countries in this field has been confirmed in previous literature [28-30, 35-36, 39]. For instance, Li et al. [35] identified 144 papers published in the International Journal of STEM Education from 2014 to 2018 and reported that three-quarters of publications were from the US over the 4-year period, followed by Australia and Canada. Furthermore, Ozkaya [28] identified 2313 studies taken from the Web of Science database between 1992 and 2017. He reported that the US had the highest contribution to STEM education research, followed by the UK and Australia. More recently, Gil-Domenech et al. [30] presented the list of 15 institutions with a greater quantity of publications in STEM education and found out that all of these institutions originated from the US. This condition is also associated with the increasing number of funded STEM education projects in the US from 2003 to 2019 [29]. For example, for the 2020 fiscal year, the Committee on STEM Education [40] made 174 investments amounting to $\$ 3.68$ billion to support STEM-related programs across US federal agencies. 
Regarding the analysis of the publications related to STEM education according to the number of authors, it was found that most of the papers had 3 authors (i.e., 23.81\%). In fact, $87.79 \%$ of publications were written by at least 2 authors. The current findings are in line with the study conducted by Li et al. [29]. In their systematic review, of the 798 papers, $83.7 \%(n=668)$ were written by two or more authors and only $16.3 \%$ were single-author papers. In addition, Gil-Domenech et al. [30] reported that of the 15 most cited papers in STEM education, 11 papers were written by at least 3 authors, 3 papers with 2 authors, and only 1 paper with a single author. The results show a dramatic increase in research collaborations within a country and across countries in STEM education. In brief, there is an increasing interest in research collaboration and a positive trend in publications in STEM education, implying that the number of papers with joint authorships is likely to increase in the future.

\section{Conclusions}

In conclusion, the number of publications in STEM education seemed to progress rapidly in the last decade, despite an unequal contribution between countries around the world. Publications from the US, where STEM education originates, and other developed countries still dominated; that developing countries need to perform greater efforts in the future. Interestingly, the number of multi-author papers grew rapidly over the 10-year period. This shows that a good STEM research community has been formed between institutions both within a country and across countries. In addition, amid the rapid changes in STEM education research, quantitative methods have been the most popular research design among STEM researchers. It can be argued that these methods were preferred because they offer an easier process even when the research involves large sample sizes.

\section{$6 \quad$ Limitations}

It is hoped that the results of this study will help researchers and educators in STEM education in conducting and publishing their work. Even though this study has been successful in mapping new directions and identifying recent developments in STEM education research, this study still suffers from several limitations, such as the limited number of journals to analyze. Thus, a broader range of journals and a longer period of research are needed. In addition, this study only identified and examined papers published in scientific journals. Future researchers are suggested to include, for example, book chapters, book reviews, and conference papers in the analysis for more comprehensive insights. More importantly, it is encouraged that other variables such as types of participants, research designs, sampling techniques, sample sizes, data collection, data analysis, and research topics are used in further research. 


\section{$7 \quad$ References}

[1] Howard, G. S., Cole, D. A., \& Maxwell, S. E. (1987). Research productivity in psychology based on publication in the journals of the American Psychological Association. American Psychologist, 42(11), 975-986. https://doi.org/10.1037/0003-066X.42.11.975

[2] Maass, K., Geiger, V., Ariza, M. R., \& Goos, M. (2019). The role of mathematics in interdisciplinary STEM education. ZDM Mathematics Education, 51, 869-884. https://doi.org/ 10.1007/s11858-019-01100-5

[3] Moore, T., Stohlmann, M., Wang, H., Tank, K., Glancy, A., \& Roehrig, G. (2014). Implementation and integration of engineering in K-12 STEM education. In S. Purzer, J. Strobel, \& M. Cardella (Eds.), Engineering in Pre-College Settings: Synthesizing Research, Policy, and Practices (pp. 35-60). Purdue University Press. https://doi.org/10.2307/j.ctt6wq7bh.7

[4] Johnson, C. C. (2013). Conceptualizing integrated STEM education. School Science and Mathematics, 113(8), 367-368. https://doi.org/10.1111/ssm.12043

[5] Martin-Paez, T., Aguilera, D., Perales-Palacios, F. J., \& Vílchez-González, J. M. (2019). What are we talking about when we talk about STEM education? A review of literature. Science Education, 103(4), 799-822. https://doi.org/10.1002/sce.21522

[6] Kelley, T. R., \& Knowles, J. G. (2016). A conceptual framework for integrated STEM education. International Journal of STEM Education, 3(11), 1-11. https://doi.org/10.1186/ s40594-016-0046-Z

[7] Stohlmann, M., Moore, T., \& Roehrig, G. (2012). Considerations for teaching integrated STEM education. Journal of Pre-College Engineering Education Research, 2(1), 28-34. https://doi.org/10.5703/1288284314653

[8] Kim, Y., Chu, H. E., \& Lim, G. (2015). Science curriculum changes and STEM education in east Asia. In M. S. Khine (Ed.), Science Education in East Asia: Pedagogical Innovations and Research-informed Practices (pp. 149-226). Springer. https://doi.org/ 10.1007/978-3-319-16390-1 7

[9] Potvin, P., \& Hasni, A. (2014). Analysis of the decline in interest towards school science and technology from grades 5 through 11. Journal of Science Education and Technology, 23(6), 784-802. https://doi.org/10.1007/s10956-014-9512-x

[10] Wahono, B., Lin, P. L. \& Chang, C. Y. (2020). Evidence of STEM enactment effectiveness in Asian student learning outcomes. International Journal of STEM Education, 7, 36. https:// doi.org/10.1186/s40594-020-00236-1

[11] Wang, X. (2013). Why students choose STEM majors: Motivation, high school learning, and postsecondary context of support. American Educational Research Journal, 50(5), 1081-1121. https://doi.org/10.3102/0002831213488622

[12] Roberts, A. (2012). A justification for STEM education. Technology and engineering teacher, 1-5. https://www.iteea.org/File.aspx?id=86478\&v=5409fe8e

[13] Sadler, P. M., Sonnert, G., Hazari, Z., \& Tai, R. (2012). Stability and volatility of STEM career interest in high school: A gender study. Science Education, 96(3), 411-427. https:// doi.org/10.1002/sce.21007

[14] Kennedy, J., Lyons, T., \& Quinn, F. (2014). The continuing decline of science and mathematics enrolments in Australian high schools. Teaching Science, 60(2), 34-46.

[15] Beach, A. L., Henderson, C., \& Finkelstein, N. (2012). Facilitating change in undergraduate STEM education. Change: The Magazine of Higher Learning, 44(6), 52-59. https://doi.org/10.1080/00091383.2012.728955

[16] Sharma, J., \& Yarlagadda, P. K. (2018). Perspectives of "STEM education and policies" for the development of a skilled workforce in Australia and India. International Journal of Science Education, 40(16), 1999-2022. https://doi.org/10.1080/09500693.2018.1517239 
[17] Huri, N. H. D., \& Karpudewan, M. (2019). Evaluating the effectiveness of integrated STEM-lab activities in improving secondary school students' understanding of electrolysis. Chemistry Education Research and Practice, 20(3), 495-508. https://doi.org/10.1039/ C9RP00021F

[18] Aydin-Gunbatar, S., Ekiz-Kiran, B., \& Oztay, E. S. (2020). Pre-service chemistry teachers' pedagogical content knowledge for integrated STEM development with LESMeR model. Chemistry Education Research and Practice, 21(4), 1063-1082. https://doi.org/10.1039/ D0RP00074D

[19] Ciftci, A., Topcu, M. S., \& Foulk, J. A. (2020). Pre-service early childhood teachers' views on STEM education and their STEM teaching practices. Research in Science \& Technological Education, 1-27. https://doi.org/10.1080/02635143.2020.1784125

[20] Moore, T. J., Johnson, C. C., Peters-Burton, E. E., \& Guzey, S. S. (2016). The need for a STEM road map. In C. C. Johnson, E. E. Peters-Burton \& T. J. Moore (Eds.), STEM road map: A framework for integrated STEM education. Routledge. https://doi.org/ $10.4324 / 9781315753157$

[21] Tzagkaraki, E., Papadakis, S., \& Kalogiannakis, M. (2021). Exploring the use of educational robotics in primary school and its possible place in the curricula. In M. Malvezzi, D. Alimisis, \& M. Moro (Eds.), Educational Robotics International Conference (pp. 216-229). Springer. https://doi.org/10.1007/978-3-030-77022-8 19

[22] Papadakis, S. (2020). Evaluating a teaching intervention for teaching STEM and programming concepts through the creation of a weather-forecast app for smart mobile devices. In M. Kalogiannakis \& S. Papadakis (Eds.), Handbook of Research on Tools for Teaching Computational Thinking in P-12 Education (pp. 31-53). IGI Global. https://doi. org/10.4018/978-1-7998-4576-8.ch002

[23] Struyf, A., De Loof, H., Boeve-de Pauw, J., \& Van Petegem, P. (2019). Students' engagement in different STEM learning environments: Integrated STEM education as promising practice? International Journal of Science Education, 41(10), 1387-1407. https://doi.org/10 $.1080 / 09500693.2019 .1607983$

[24] DeCoito, I. (2016). STEM education in Canada: A knowledge synthesis. Canadian Journal of Science, Mathematics and Technology Education, 16(2), 114-128. https://doi.org/10.108 0/14926156.2016.1166297

[25] Montgomery, C., \& Fernández-Cárdenas, J. M. (2018). Teaching STEM education through dialogue and transformative learning: Global significance and local interactions in Mexico and the UK. Journal of Education for Teaching, 44(1), 2-13. https://doi.org/10.1080/02607 $\underline{476.2018 .1422606}$

[26] Kang, N.-H. (2019). A review of the effect of integrated STEM or STEAM (science, technology, engineering, arts, and mathematics) education in South Korea. Asia-Pacific Science Education, 5(1), 6. https://doi.org/10.1186/s41029-019-0034-y

[27] Bozkurt, A., Ucar, H., Durak, G., \& Idin, S. (2019). The current state of the art in STEM research: A systematic review study. Cypriot Journal of Educational Science, 14(3), 374-383. https://doi.org/10.18844/cjes.v14i3.3447

[28] Ozkaya, A. (2019). Bibliometric analysis of the publications made in STEM education area. Bartın University Journal of Faculty of Education, 8(2), 590-628. https://doi.org/10.14686/ buefad. 450825

[29] Li, Y., Wang, K., Xiao, Y., \& Froyd, J. E. (2020). Research and trends in STEM education: A systematic review of journal publications. International Journal of STEM Education, 7, 11. https://doi.org/10.1186/s40594-020-00207-6

[30] Gil-Domenech, D., Berbegal-Mirabent, J., \& Merigo, J. M. (2020). STEM education: A bibliometric overview. Advances in Intelligent Systems and Computing, 894, 193-205. https://doi.org/10.1007/978-3-030-15413-4_15 
[31] Takeuchi, M. A., Sengupta, P., Shanahan, M.-C., Adams, J. D., \& Hachem, M. (2020). Transdisciplinarity in STEM education: A critical review. Studies in Science Education, 56(2), 213-253. https://doi.org/10.1080/03057267.2020.1755802

[32] Petticrew, M. \& Roberts, H. (2008). Systematic reviews in the social sciences: A practical guide. Blackwell Publishing.

[33] Tsai, C.-C., \& Wen, L. M. C. (2005). Research and trends in science education from 1998 to 2002: A content analysis of publication in selected journals. International Journal of Science Education, 27(1), 3-14. https://doi.org/10.1080/0950069042000243727

[34] Ha, C. T., Thao, T. T. P., Trung, N. T., Huong, L. T. T., Dinh, N. V., \& Trung, T. (2020). A bibliometric review of research on STEM education in ASEAN: Science mapping the literature in Scopus database, 2000 to 2019. Eurasia Journal of Mathematics, Science and Technology Education, 16(10), em1889. https://doi.org/10.29333/ejmste/8500

[35] Li, Y., Froyd, J. E., \& Wang, K. (2019). Learning about research and readership development in STEM education: A systematic analysis of the journal's publications from 2014 to 2018. International Journal of STEM Education, 6(1), 1-8. https://doi.org/10.1186/ s40594-019-0176-1

[36] Yu, Y. C., Chang, S. H., \& Yu, L. C. (2016). An academic trend in STEM education from bibliometric and co-citation method. International Journal of Information and Education Technology, 6(2), 113-116. https://doi.org/10.7763/IJIET.2016.V6.668

[37] Cohen, L., Manion, L. \& Morrison, K. (2011). Research methods in education. (7th ed). Routledge.

[38] Creswell, J. W. (2009). Research design qualitative, quantitative and mixed methods approach. (3rd ed). SAGE Publication.

[39] Sawangmek, S. (2019). Trends and issues on STEM and STEAM education in early childhood. Training and Practice, 17(3-4), 97-106. https://doi.org/10.17165/TP.2019.3-4.8

[40] National Science Technology Council. Committee on STEM Education (CoSTEM). (2020, December). Progress report on the implementation of the federal STEM education strategic plan.

\section{Authors}

Irwanto Irwanto is a lecturer at the Department of Chemistry Education, Universitas Negeri Jakarta, Jakarta 13220, Indonesia. His research areas include chemistry education, STEM education, and the effect of technology in teaching and learning. Email: Irwanto@unj.ac.id

Anip Dwi Saputro is a senior lecturer at the Faculty of Islamic Studies, Universitas Muhammadiyah Ponorogo, Ponorogo, Indonesia. His research interests include science education and educational technology.

Widiyanti is a senior lecturer at the Department of Mechanical Engineering, Universitas Negeri Malang, Malang, Indonesia. Her research interests include TPACK and STEM education.

M. Firman Ramadhan is a senior lecturer at the Department of Physics Education, Universitas Muhammadiyah Mataram, Mataram, Indonesia. His research interests include physics education, learning technology, and computational physics.

Isna Rezkia Lukman is a lecturer at the Department of Chemistry Education, Universitas Malikussaleh, Aceh, Indonesia. His research interests include chemistry education and instructional technology.

Article submitted 2021-09-19. Resubmitted 2021-11-19. Final acceptance 2022-01-06. Final version published as submitted by the authors. 